\title{
A Critical Discourse Analysis Study of Cyberbullying in LGBTQ's Instagram Account
}

\author{
Sukma Ari Ragil Putri ${ }^{1, *}$ and A.A.I Prihandari Satvikadewi ${ }^{1}$ \\ ${ }^{1}$ University of 17 Agustus 1945 Surabaya, FISIP Untag Surabaya, Jl. Semolowaru No. 45 Surabaya \\ Indonesia
}

\begin{abstract}
As the advancing of technology, bullying became online, it moved to social media, which was then called cyberbullying. Instagram is one of social media that contain a lot of cyberbullying, it usually happened to public figure. It became interesting when the public figure in the bully is LGBTQ, namely Dena Rachman (transgender). This study explored how discourse formed the logic of truth which naturalize the perpetrators to commit cyberbullying act without hesitation. This study used Critical Discourse Analysis (CDA) method and Teun A. van Dijk's analysis technique and data interpretation. This study found that the logic of truth that became the basis of cyberbullying is already a natural logic and became the perpetrator's mindset because it has been institutionalized in everyday life through education, religion, social life, and state regulations.
\end{abstract}

\section{Background}

Bullying is a negative action that is often aggressive and manipulative, performed by one person or more against another person or group of people for any given period of time, that contained with violence and imbalance of power. As the advancing of technology, bullying became online, it moved to social media. People often encounter conflicts caused by misunderstandings on social networking sites (SNS), one of which is in the form of cyberbullying.

Social media or social networking sites (SNS) was becoming increasingly rampant in recent years. Even Joost van Loon [1] stated that the term of networking is no longer representing the terminology in information technology but also in the terminology of anthropology, sociology, cultural, and social sciences fields. Networking does not just involve devices such as computers but also involves an individual or networking actor [1]. Social media can make communication between humans become borderless because people can communicate with anyone in any country at any time. Aside from being a medium to communicate with others directly, social media becomes a medium for communicating a person's identity.

\footnotetext{
*Corresponding author: sukmaariragilputri@gmail.com
} 
Uploading photos on social media is one of the way a person communicating their identity to others. While the likes and comments are a form of interaction. Interaction is a concept that has been used to distinguish the traditional media with new media. According to Graham [1] the presence of communication technologies are basically provide the opportunity for anyone to interact easily, and connect to each other without the constraints of distance and time. Technology has became a medium of all human activity.

Manovich [1] revealed that in fact, the concept of interaction in the new media made boundaries of the physical and social interaction begin to blur. For example, resident of country A can easily interact with the resident of country B without having to meet before. Resident of country A can also praise or denounce the resident of country B without inhibitions, even if it turns out the resident of country B is a public figure. This is where the physical and social boundaries begin to blur. Social media eventually become a new container to the marginalization of the groups or people who are considered incompatible with the existing normative order in society, one of which is LGBTQ.

\section{Teminologies to LGBTQ Understanding}

LGBTQ identity has been regarded as something different. Before discussing about LGBTQ identity, we need to understand the most important terminology regarding human sexuality first. There are gender identity, sexual orientation, and sexual behavior. People tend to misunderstand those three terminologies as a single unit which caused confusion and wrong meaning.

Gender identity is often misunderstood as sex. However, those two things are like chalk and cheese, very different. Sex was categorized based on the physical characteristics or biological characteristics of human. For example, man was characterized by having penis, testicles, and sperm, while woman was characterized by having vagina, ovum, and uterus. Those biological characteristics are natural and cannot be changed, except for the genital parts that can be modified with the advancing of technology. However, the modification will never change its function [2].

In contrast to sex, gender identity was a social construction. It refers to a set of roles, functions, rights, responsibilities, and behaviors of man and woman that constructed by people based on culture, social, economy, and politic situation. For instance, man was constructed as a gender that has masculine traits such as strong, bold, rational, and tough. This world was kind of black and white, it always been applying binary opposition concept. Therefore, when there was strong, there was weak. That is why woman was constructed as a gender that has feminine traits such as weak, fearful, irrational, emotional, and fragile.

A fatal error occurs when masculine and feminine were regarded as natural as sex. Yet according to psychological study, every human being has masculine and feminine traits since they were born. However, as they grow up, the tendency of a person's masculinity and femininity are influenced by parenting, cultural values, education in the formal school system, and the interpretation of religion values. According to Judith Butler [3], the masculine gender is not always in man's body, as well as feminine gender is not always in woman's body. Furthermore, there is no reason to assume gender also categorized into two like sex.

Butler's opinion was based on Simone de Beauvoir's statement in The Second Sex that suggest that someone was not born a woman but rather become a woman. For her, gender was constructed. She explained that a person that become a woman was under culturally duress to be female with all of its feminine traits. And clearly for her, that compulsion does not come from biological sex. There is no a guarantee or provitions that a person who become a woman needs to be female [3]. 
The second most important terminology is sexual orientation. Sometimes people confuse with gender identity and sexual orientation. For instance, people assume that a man who has feminine traits also like man. Though not necesseraly the case. As described previously, gender identity is a social construction whereas sexual orientation is a natural thing and cannot be changed. Someone cannot choose to be born with a particular sexual orientation. Being heterosexual, homosexual, bisexual, and asexual is not an option, nor because of social construction [2].

Similar opinion was expressed by Suryakusuma [4]. In one of his paper, he said that the concept of gender identity is often confused with the concept of sexuality. According to him, gender identity is psychological and cultural expressions of gender that evolve into specific roles and behaviors that then identified with specific sex. The third terminology is sexual behavior. It can be understood as a way of expressing someone's sexual relationship. Sexual behavior is strongly influenced by social construction because it can be learned and not a natural conditions.

Those three terminologies, gender identity, sexual orientation, and sexual behavior, each of them has category that considered normal and abnormal by social convention. For example, normal gender identity would be masculine man and feminine woman. Normal sexual orientation would be heterosexual, and normal sexual behavior would be penetration of penis into vagina. Other identity, orientation, and behavior outside that normal category then categorized as LGBTQ which is a category that accommodate individuals who are considered abnormal by social convention.

\section{LGBTQ and Instagram}

On daily life, LGBTQ have been bullied all the time in many ways by people who thinks they are abnormal. It becomes interesting when LGBTQ begin to express their identity on social media, one of it, is Instagram. Social media as a medium for people to express their thought, feeling, expressions, basically everything, become a bullying medium for minority, which is LGBTQ. People with dominant ideology tend to marginalize minority by uploading comments that were rude and judgmental. They even considered those comments as something fair and reasonable to do.

One of LGBTQ that express her new identity on Instagram is Dena Rachman. Dena Rachman was known as an Indonesian child artist with the name Renaldy Denada and famous with various songs, as well as a host of various music shows. She also starred in some of TV series. Born as a man, Dena Rachman began to change her appearance to be a woman when she studied at University of Indonesia in 2005. Her changing invited many pros and cons from people in Indonesia.

People's assumption in Dena Rachman's gender identity were various. When assumption goes one step further, it becomes bullying. People tend to say or write their assumption on Dena Rachman's Instagram. They commented on any photos uploaded by Dena Rachman with indecent comments and sometimes had nothing to do with the photos itself, they intended to attack Dena Rachman's personality and identity. Of these problems that arise within the rising of new media, I want to find out how discourse formed the logic of truth which naturalize the people to commit cyberbullying act on Dena Rachman's Instagram without hesitation by using Teun A. van Dijk's Critical Discourse Analysis.

\section{Teun A. van Dijk's CDA}

Teun A. van Dijk stated that discourse in the media cannot be separated from the concept of power and access. Power is fundamental in the formation of a discourse. Power is a tool 
that is owned by social group, institution or organization that is used to control the actions and thoughts of others, with the aim of limiting the freedom of other groups. In this case a group that are limited are a minority, namely LGBTQ.

The power of dominant party distributed through public domains such as the realm of politics, media, law, education, and business, which then resulted in different centers of power in certain groups. Power is based on the ease of access of a group on the social resources such as wealth, jobs, status, or simply access to public communication space [5]. In general, the power of media is symbolic and persuasive, the media has the potential to control the audience thought, though not directly control their actions.

In relation to social media, social media only serve as a medium. Even it merely a medium, it has the most important role. It is used as a tool to carry out the exercise of power of the dominant groups. Social media is free to be used by anyone who has access to it. In the end, it still controlled by dominant groups that even before the existence of social media had been in charge of power in real life. In this study, the dominant group is the heterosexual community living with gender identity in accordance with their biological identity (sex). They use social media as access to perpetuate the practice of their power over subordinate groups which is LGBTQ. Social media becomes a medium for them to do an extension of marginalization in the form of cyberbullying.

Teun A. van Dijk's critical discourse analysis focused on the role of discourse in the reproduction and the challenge of dominance. Domination itself was interpreted as a social power of the elite, institution, or group, which produced social imbalance in various fields such as politics, culture, class, ethnicity, race, and gender imbalances. He thought that social inequality is not simply produced by the action of an individual, for example with the command. This imbalance was produced jointly by the parties that dominate people's thought so that their domination feels natural and legitimate [6].

This study used van Dijk's CDA based on several things. First, van Dijk [6] stated that social cognition is an important part of critical discourse analysis. Social cognition monitors discourse, communication, and all forms of action and interaction. The same thing applies to our understanding of social events or social institutions and power relations. It can be argued that social cognition becomes a medium between the micro and macro levels of society, between discourse and action, between individuals and groups. A social cognition itself has many forms including opinions, attitudes, ideologies, norms, and value. Second, this study used social media and made comments in social media as a unit of analysis. As we know it, the comments in social media were usually straightforward and comparatively brief. Therefore, it did not require very deep text analysis. This can be accommodated by van Dijk's CDA that did not require a detailed text analysis.

\subsection{Text Analysis}

Table 4.1. Text Analysis Step

Based on the picture, van Dijk's CDA has three dimensions; the text, social cognition, and social context. At text level or referred as the microstructure, we can look at how the structure of text has been used to emphasize a particular theme. In this study, first, I selected

\section{Context}

Social Cognition

Text several pictures of Dena Rachman in her Instagram account that showing the performance of her gender identity, sexual orientation, and sexual behavior. Then, from those pictures, I observed, selected, and categorized their comments. Based on initial observations, the comments that have been uploaded in Dena Rachman's Instagram account can be divided 
in three main context; (1) physical context, the comments that discuss the body, (2) identity context, the comments that discuss the victim's identity, (3) religious context, the comments that brought religion issues. Those comments that consist of multiple context will be analyzed by looking for their meaning regarding to the choice of words and sentences by using some elements of discourse proposed by van Dijk.

\subsection{Social Cognition Analysis}

At the level of social cognition, I studied the text production that involves social cognition of the text producer. As I mentioned earlier, social cognition many forms such as ideology, values, attitudes, and norms that can be known by conducting in-depth interviews to determine the social cognition of text producer .In this study, I chose the most one commentator that uploaded negative comments all the time in Dena Rachman's Instagram account. To understand the social cognition, van Dijk used scheme. He called it as a model of mental structure that includes how we see other human being [5].

Table 4.2. Social Cognition Analysis Step

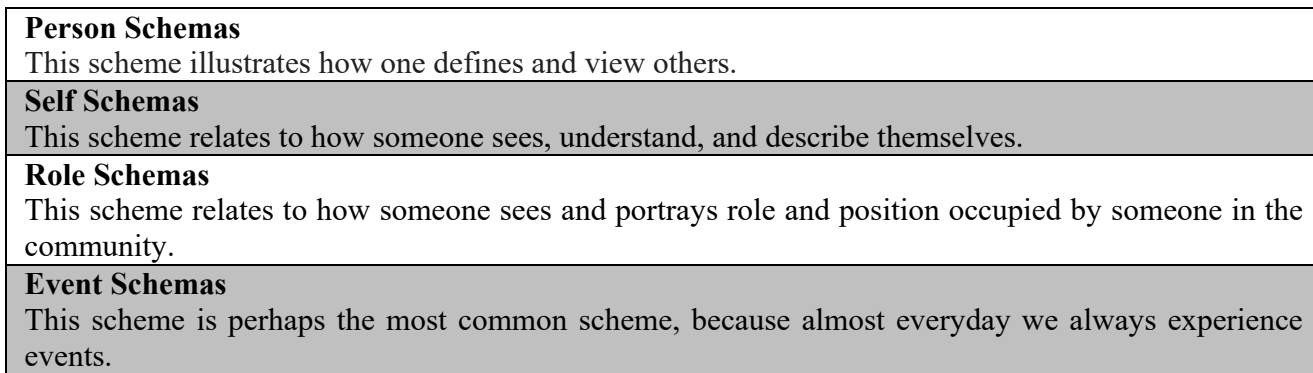

Model or the scheme is a central element in van Dijk's framework, because the interpretation of an event based on this model. Therefore, the model or the scheme is an important guide to this study.

\subsection{Social Context Analysis}

The third level to understand discourse construction is social context. Discourse is part of a growing discourse in society. In the study of discourse, to understand the discourse, we need to understand the social context that manufactured and constructed in the community. In this study, I analyzed how the LGBTQ discourse developed in the community by using scientific literature or history research. According to van Dijk, there are two important point, which are power and access.

Van Dijk defines power as the ownership that owned by a group (or members) for the control of the other group. His CDA gave considerable attention to the so-called domnination, wether domination of race, religion, social class, gender, etc. Domination reproduced by granting special access to one group than the other group. He also drew attention to the discourse production process through legitimate mind control. If controlling discourse is a first major form of power, controlling people's minds is the other fundamental way to reproduce dominance and hegemony. Mind control involves even more than just acquiring beliefs about the world through discourse and communication. Suggested below are ways that power and dominance are involved in mind control. First, recipients tend to accept beliefs, knowledge, and opinions (unless they are inconsistent with their personal beliefs and experiences) through discourse from what they see as 
authoritative, trustworthy, or credible sources, such as scholars, experts, professionals, or reliable media. Second, in some situations participants are obliged to be recipients of discourse, e.g. in education and in many job situations or in daily life [7].

\section{Practice of Power and Access Affect LGBTQ Discourse}

Based on comment analysis on Dena Rachman's Instagram, I found out that Dena Rachman who has a proportional body and dress up like 'real' woman accept bullying in the form of words which attacks the physical characteristics related to sex, such as the word breast (boobs, tits, etc), genitals (penis), and also deals with such physical authenticity of the results of surgery or not. In addition, Dena Rachman is a transgender, and now she is in the process of sex reassignment surgery. He was attacked in the form of comments by the words mentioning that transgender is a bad thing, like the word pansy, 'bencong', 'waria', etc.

Furthermore, from interviews with several comentators, I obtained a judgment that they position themselves on a higher position than Dena Rachman. Moreover, by looking at how they put forward the issue of ethics and religion to bully Dena Rachman, suggested that they position themselves as a party who have a better understanding of ethics and religion than Dena Rachman. It is happening because they feel that the correct identity according to the provisions of the religion is the identity of the 'normal', heterosexual, masculine men and feminine women. Identity outside those criterias are inappropriate. Associated with the widespread use of social media Instagram and many LGBTQ that express themselves in social media, the commentators felt uncomfortable with that event. Based on the results of in-depth interviews, all of them admitted that it is inappropriate that LGBTQ express their identity in the form of photos on Instagram.

Then I associated the findings above with van Dijk's two main concepts, practice of power and access. Practice of power that occurred in this study were happened when people with 'normal' gender identity (heterosexual, masculine male and female feminine) have domination of the minority group in Indonesia, identities which are considered 'weird' and abnormal (lesbian, gay, bisexual, transgender, queer). Domination by van Dijk [5] is understood as a form of social power abuse that is legally and morally a legitimate practice of control over other people's personal interests, which often leads to social inequality.

Based on the analysis of comments and analysis of social cognition in the previous stages, I saw that commentators' thought or logic about the identity of LGBTQ has been formed early on, because the education of parents and the surrounding environment, which then unknowingly been embedded into the mindset and even life principle then they passed to their descendants. Logic formed since childhood then generate attitudes, behavior, and positioning as reflected in the comments and social cognition of commentators. It becomes interesting when it appears one space, a new medium, for LGBTQ people to express their identity. The new medium is social media, which is Instagram. In practice, the logic of truth in the communities associated with LGBTQ, still on the same page as before. They carry wherever they are, even if it's in social media. This is why cyberbullying in Instagram against LGBTQ was arisen.

The second concept of van Dijk's CDA is access. According to van Dijk, access affects discourses. Teun A. van Dijk [6] put greater emphasis on how to access between each group in society. The group that dominates have greater access than the group who are not in power. Therefore, those in power have a greater chance to have access to media, and greater opportunities to influence public awareness. With their access to influence the discourse on Instagram, making them more free to express all forms of resentment and hatred. 


\section{Conclusion}

'Manual' bullying requires face to face interaction between the offender and the victim, but now it moved to the virtual world which is then referred to as cyberbullying. Perpetrators do cyberbullying to the figures which are considered to have the identity out of the ordinary, in this case is transgender. They give negative comments and tend to be rough on transgender's Instagram account. The logic of truth raised by the commentators on Instagram is already become their mindset because it has been institutionalized in everyday life through education, social life, and state regulations. They feel threatened with something outside the 'normality'.

One thing we should understand is technology will continue to develop and it is very possible that LGBTQ people will express theirselves in other social media when people restrict their expression in Instagram. I concluded that the public itself is still overlap between accepting the existence of LGBT as a reality that must be faced or support their existence. Here, I hope the community, not stuck on the logic of normative truth, and although not yet to accept the existence of LGBT people, but at least they do not do rejection and attacks against LGBT.

\section{References}

1. R. Nasrullah, Teori dan Riset Media Siber (Cybermedia), (Kencana Prenadamedia Group, Jakarta, 2014)

2. Mulia, Siti Musdah, Islam dan Homoseksualitas: Membaca Ulang Pemahaman Islam, (Jurnal Gandrung 1(1): 9-31, 2010)

3. J. Butler, Gender Trouble, (Routledge, New York, 1990)

4. Suryakusuma, Julia I, Konstruksi Sosial Seksualitas: Sebuah Pengantar Teoritis, (Prisma: 3-14, 1991)

5. T. A. van Dijk, Discourse, Power and Access, (Routledge, London, 1996)

6. T. A. van Dijk, Principles of Discourse Analysis. Discourse \& Society, J. E 4, 2 (1993)

7. T. A. van Dijk, Power and The News Media, (Hampton Press, New Jersey, 1995) 